\title{
The mechanism of and the association between interleukin-27 and chemotherapeutic drug sensitivity in lung cancer
}

\author{
BINGDONG JIANG ${ }^{1}$, WENBO SHI $^{2}, \mathrm{PENG} \mathrm{LI}^{3}$, YANLI WU ${ }^{4}, \mathrm{YUN} \mathrm{LI}^{1}$ and CHUANMING BAO ${ }^{5}$ \\ ${ }^{1}$ Department of Medical Oncology, Jingmen No. 1 People's Hospital, Jingmen, Hubei 448000; ${ }^{2}$ Department of Oncology, \\ The Central Hospital of Enshi Autonomous Prefecture, Enshi, Hubei 445000; ${ }^{3}$ Department of Radiotherapy, \\ Jingmen No. 1 People's Hospital, Jingmen, Hubei 448000; ${ }^{4}$ Department of Oncology, Guangshui No. 1 \\ People's Hospital, Guangshui, Hubei 432700; ${ }^{5}$ Department of Cardiothoracic Surgery, \\ Suizhou Central Hospital, Suizhou, Hubei 441300, P.R. China
}

Received May 22, 2018; Accepted April 12, 2019

DOI: $10.3892 / \mathrm{ol} .2020 .12275$

\begin{abstract}
Interleukins (ILs) are involved in the occurrence and development of numerous types of cancer, and serve a critical role in the development of effective cancer therapeutics. The aim of the present study was to investigate the effect of IL-27 on chemotherapy resistance in lung cancer cells, and analyze its potential molecular mechanism in lung cancer tissues. Western blot analysis and reverse transcription-quantitative polymerase chain reaction were performed to examine the RNA and protein expression levels of IL-27. A Cell Counting Kit-8 assay was performed to evaluate the proliferation rates of the lung cancer line A549. Flow cytometry was subsequently applied to determine the rate of apoptosis in A549 cells. The data obtained revealed that the expression of IL-27 with cisplatin, significantly suppressed the proliferation and apoptosis of A549 cells compared with that in the cisplatin treatment group alone. The expression of Akt and apoptosis factors such as Caspase-3 and $\mathrm{Bcl}-2 / \mathrm{Bax}$ also ascertained that upregulated IL-27 inhibited the development of cancer and increased apoptosis in the A549 cells. Therefore, IL-27 may represent a potential target for antitumor therapy, especially when considering the clinical challenges presented by the development of chemoresistance in tumors. These findings suggest that IL-27 is a promising biomarker and represents a novel treatment strategy for patients with lung cancer.
\end{abstract}

\section{Introduction}

Lung cancer is the leading cause of cancer-associated mortality worldwide, and the incidence of this disease is increasing incrementally (1). There are nearly one million newly diagnosed cases

Correspondence to: $\mathrm{Dr}$ Chuanming Bao, Department of Cardiothoracic Surgery, Suizhou Central Hospital, 60 Longmen Street, Suizhou, Hubei 441300, P.R. China

E-mail: dr_chuanmingbao@sina.com

Key words: interleukin-27, lung cancer, Akt, chemotherapy resistance annually, and the incidence is increasing at a rate of $26.96 \%$ each year worldwide (2). At present, despite the development of chemotherapy, radiotherapy and molecular targeted therapy (3-5), the 5-year survival rate for patients with lung cancer remains unsatisfactory $(6,7)$. The resistance of cancer cells to anticancer drugs is a principal reason for the reduced curative effect of chemotherapy (8). Therefore, it is imperative to understand the potential molecular mechanisms governing lung cancer metastasis and recurrence, and to identify effective molecular markers.

At present, the standard therapy for lung cancer is surgical intervention followed by combination chemotherapy, consisting of Taxol and platinum-based drugs (9). Cisplatin is one of the most effective non-specific drugs administered for the treatment of lung cancer $(10,11)$, and Taxol is a primary chemotherapeutic agent. Combination therapy with cisplatin serves a pivotal role in the treatment of lung cancer (12). The development of drug resistance has become a principal cause of poor survival rates in patients with lung cancer (8). Chemoresistance is a prevalent clinical challenge resulting in treatment failure and recurrence (13), and, consequently, there is an urgent need to develop targeted solutions to overcome drug resistance, based on the distinct molecular background of lung cancer and the mechanisms of platinum-based drug resistance.

Cytokines, including interleukins (ILs), interferons, cancer necrosis factors, colony stimulating factors, chemokines and growth factors, serve an important role in immune regulation $(14,15)$. Cytokines also participate in the occurrence and development of a variety of diseases, including acute or chronic inflammatory disease, autoimmune disease and cancers (16). Changes in the expression levels of cytokines can regulate the immune response (17). ILs are soluble proteins secreted by a group of white blood cells, which can adjust the function of white blood cells and tissues (18). ILs are primarily involved in the activation and regulation of immune cells, T-cell and B-cell proliferation, differentiation and inflammation (19). Numerous ILs, such as IL-6 and IL-33, are closely associated with gastric cancer $(20,21)$. IL-27, a member of the cytokine family, exhibits antitumor cell proliferation and antiangiogenetic properties (22-25). However, the roles of IL-27 in lung cancer cells, chemotherapeutic sensitivity and drug resistance mechanisms have not been completely elucidated. 
The aim of the present study was to investigate the effect of IL-27 on chemotherapy resistance in the A549 lung cancer cell line and analyze its potential molecular mechanism in lung cancer tissues. This may provide a theoretical basis for the development of more effective cancer therapeutics.

\section{Materials and methods}

Tissue samples. A total of 60 patients with lung cancer were included in the present study, and 30 cancer and 30 normal tissues ( $\geq 5 \mathrm{~cm}$ from tumor) were obtained. Patients (32-73 years; mean age, $51 \pm 20.9$ years) were recruited at Suizhou Central Hospital (Suizhou, China) between August 2015 and December 2016, and all provided written informed consent prior to resection. The patients enrolled in this study had not received prior chemotherapy and radiotherapy. The present study was approved by the Ethics Committee of Suizhou Central Hospital (Suizhou, China). All patients provided the informed consent. Tissue samples were stored in liquid nitrogen at $-80^{\circ} \mathrm{C}$ until subsequent experimentation. The clinical information of the patients is presented in Table I.

Cell culture and treatment. The lung adenocarcinoma cell line A549 was obtained from the American Type Culture Collection (Manassas, VA, USA). Cells were cultured in RPMI-1640 (Gibco; Thermo Fisher Scientific, Inc., Waltham, MA, USA) supplemented with $10 \%$ fetal bovine serum (HyClone; GE Healthcare Life Sciences, Logan, UT, USA), $100 \mathrm{U} / \mathrm{ml}$ penicillin and $100 \mu \mathrm{g} / \mathrm{ml}$ streptomycin (Invitrogen; Thermo Fisher Scientific, Inc.) in an incubator with $5 \% \mathrm{CO}_{2}$ at $37^{\circ} \mathrm{C}$. Cells were passaged every other day. Cells in the logarithmic phase were selected for experimentation and divided into three groups: i) Cisplatin, ii) cisplatin + IL-27, and iii) the control group. The A549 cells were treated with or without $50 \mathrm{ng} / \mathrm{ml}$ of IL-27 at $37^{\circ} \mathrm{C}$. Following treatment with IL-27 for $72 \mathrm{~h}$, the cisplatin (40 $\mu \mathrm{M}$, Sigma-Aldrich; Merck KGaA, Darmstadt, Germany) + IL-27 group and the cisplatin-only group were treated with $40 \mu \mathrm{M}$ cisplatin at $37^{\circ} \mathrm{C}$ for $48 \mathrm{~h}$.

Reverse transcription-quantitative polymerase chain reaction (RT-qPCR). Total RNA of cells and tissues were extracted using TRIzol ${ }^{\circledR}$ reagent (Invitrogen; Thermo Fisher Scientific, Inc.). The concentration and purity of RNA were determined by spectrophotometry. Following RNA extraction, a PrimeScript $^{\mathrm{TM}}$ one step RT-PCR kit (Takara Biotechnology Co., Ltd., Dalian, China) was used for cDNA synthesis at $72^{\circ} \mathrm{C}$ for $10 \mathrm{~min}$. RT-qPCR was performed to amplify the cDNA template using a SYBR ${ }^{\circledR}$ premix dimmer eraser kit (Takara Biotechnology Co., Ltd.), performed according to the manufacturer's protocol. The thermocycling conditions were as follows: Denaturing for $5 \mathrm{~min}$ at $95^{\circ} \mathrm{C}, 40$ cycles of $10 \mathrm{sec}$ at $95^{\circ} \mathrm{C}$ and an extension for $1 \mathrm{~min}$ at $60^{\circ} \mathrm{C}$. GAPDH was used as an internal control, and mRNA values were normalized to GAPDH. The expression levels were quantified using the $2^{-\triangle \Delta C q}$ method (26). In addition, the expression of Bax, Bcl-2, caspase-3 and Akt were compared among the experimental groups. The sequences of the primers were: IL-27 forward, 5'-AGCCTTCGCATCATCAGC-3' and reverse, 5'-TTATTG GGCACCCAGCAT-3'; Bax forward, 5'-TCCACCAAGAAG CTGAGCGAG-3' and reverse, 5'-GTCCAGCCCATGATG
GTTCT-3'; Bcl-2 forward, 5'-TTCTTTGAGTTCGGTGGG GTC-3' and reverse, 5'-TGCATATTTGTTTGGGGCAGG-3'; caspase-3 forward, 5'-AGGACTCAAACTGTTGCCACC-3' and reverse, 5'-TGGAACAAATGACCTGTTGACC-3'; Akt forward, 5'-GCAGCACGTGTACGAGAAGA-3' and reverse, 5'-GTGTCAGTCTCCGACGTG-3'; and GAPDH forward, 5'-AGAAGGCTGGGGCTCATTTG-3' and reverse, 5'-AGG GGCCATCCACAGTCTTC-3'.

Western blot analysis. The cells and tissue samples were collected following treatment with cisplatin and IL-27, and lysed with RIPA lysis buffer (Beyotime Institute of Biotechnology, Haimen, China) on ice. The supernatant was retained to detect the protein concentration following high-speed by centrifugation at $12,000 \mathrm{x} \mathrm{g}$ for $20 \mathrm{~min}$ at $4^{\circ} \mathrm{C}$. The protein concentration was determined using a BCA kit (Pierce; Thermo Fisher Scientific, Inc.). Equivalent protein samples (50 $\mu \mathrm{g} /$ lane) were loaded onto $10 \%$ SDS-PAGE gels, and then transferred to polyvinylidene fluoride membranes. The membranes were blocked with $5 \%$ skimmed milk for $2 \mathrm{~h}$ at $37^{\circ} \mathrm{C}$. The primary antibodies were as follows: Anti-Bax (1:1,000; cat. no. B3428), anti-Bcl-2 (1:1,000; cat. no. PRS3335), anti-caspase-3 (1:1,000, cat. no. C8487), anti-Akt (1:1,000; cat. no. SAB4500796), anti-GAPDH (1:100; cat. no. G9545; all from Sigma-Aldrich; Merck $\mathrm{KGaA}$ ). The membrane was incubated with the primary antibodies overnight at $4^{\circ} \mathrm{C}$ and were then treated with the HRP-conjugated secondary antibodies (1:5,000; cat. no. R2655, Sigma-Aldrich; Merck KGaA, Darmstadt, Germany) at room temperature for $1 \mathrm{~h}$. Blots were evaluated using an ECL Plus immunoblotting detection system (Thermo Fisher Scientific, Inc.) and quantified by densitometry using Gel-Pro analyzer software version 6.3 (Media Cybernetics).

Cell Counting Kit-8 (CCK-8) proliferation assay. Following 48-h treatment, Cell proliferation in vitro was evaluated using a CCK-8 assay (Dojindo Molecular Technologies, Inc., Kumamoto, Japan). Cells were divided into 3 groups: Control, cisplatin and cisplatin + IL-27. Lung cancer cells were seeded separately into 96 -well plates at a density of $5.0 \times 10^{3}$ cells/well and incubated with serum-free DMEM (HyClone; GE Healthcare Life Sciences Logan, UT, USA) at $37^{\circ} \mathrm{C}$ (final volume of $100 \mu \mathrm{l}$ ) for $48 \mathrm{~h}$. A total of $10 \mu \mathrm{l} \mathrm{CCK}-8$ was added into each well and incubated for an additional $2 \mathrm{~h}$. The absorbance of each sample was measured at $450 \mathrm{~nm}$ using a microplate reader.

Flow cytometry. Following 48-h treatment, A549 cells were divided into 3 groups: Control, cisplatin and cisplatin + IL-27. Cells were collected and re-suspended in binding solution at a concentration of $5.0 \times 10^{5}$ cells $/ \mathrm{ml}$. Cells were transferred to a flow tube (100 $\mu \mathrm{l} /$ tube) and then incubated for $5 \mathrm{~min}$ with $5 \mu \mathrm{l}$ Annexin V/FITC (Nanjing KeyGen Biotech, Co., Ltd., Nanjing, China) for $15 \mathrm{~min}$ at room temperature. At the end of incubation, cells were washed three times with ice-cold PBS and the fluorescence intensity of cells was measured using a FACScalibur flow cytometer (BD Biosciences, Franklin Lakes, NJ, USA) and analyzed by FlowJo 7.6.1 software (Tree Star, Inc.).

Statistical analysis. SPSS v19.0 software (IBM Corp., Armonk, NY, USA) was used to analyze the data obtained by the present 
Table I. Clinical information of the patients.

\begin{tabular}{lccr}
\hline Characteristic & Total, $\mathrm{n}$ & $\begin{array}{c}\text { Relative IL-27 } \\
\text { expression }\end{array}$ & P-value \\
\hline $\begin{array}{l}\text { Age, years } \\
\quad 60\end{array}$ & 14 & $0.513 \pm 0.015$ & 0.319 \\
$\geq 60$ & 16 & $0.508 \pm 0.012$ & \\
Sex & & & 0.304 \\
$\quad$ Male & 18 & $0.511 \pm 0.008$ & \\
$\quad$ Female & 12 & $0.515 \pm 0.013$ & \\
Tumor differentiation & & & 0.006 \\
$\quad$ Well/moderate & 17 & $0.521 \pm 0.021$ & \\
$\quad$ Poor & 13 & $0.503 \pm 0.007$ & \\
Metastasis & & & $<0.001$ \\
$\quad$ Absent & 19 & $0.519 \pm 0.015$ & \\
$\quad$ Present & 11 & $0.497 \pm 0.009$ & \\
\hline
\end{tabular}

study. Data are presented as the mean \pm standard deviation of at least three independent experiments. A two-tailed Student's t-test was applied to analyze the difference between two groups. One-way analysis of variance followed by a Newman-Keuls post-hoc test was employed to analyze differences among three groups. $\mathrm{P}<0.05$ was considered to indicate a statistically significant difference.

\section{Results}

The expression of IL-27 and clinical characteristics. The results of patient clinical information analysis demonstrated that the expression levels of IL-27 were significantly associated with tumor differentiation and lymphatic metastasis, whereas no significant differences were observed between IL-27 expression and age or sex (Table I).

IL-27 expression is suppressed in lung cancer tissues. The expression of IL-27 in lung cancer and adjacent tissues was evaluated using RT-qPCR and western blot analysis. The results demonstrated that the expression of IL-27 was significantly suppressed in cancer tissues when compared with that in the paracarcinoma tissues $(\mathrm{P}<0.01)$. The results of the western blot analysis were consistent with those obtained by RT-qPCR, with IL-27 being expressed at a low level in cancer tissues (Fig. 1). These results suggest that IL-27 exhibits low expression levels in lung cancer tissue.

Proliferation ability and cell apoptosis of A549 lung cancer cells. A CCK-8 assay was conducted to evaluate cell proliferation ability (Fig. 2), and an apoptosis assay was performed to evaluate cell apoptosis (Fig. 3). The results of the CCK-8 assay demonstrated that, compared with the control group, treatment with cisplatin significantly promoted apoptosis and inhibited proliferation in lung cancer cells $(\mathrm{P}<0.01)$. The A549 cells treated with cisplatin + IL-27 exhibited a significant increased rate of apoptosis, and the ability to suppress proliferation was also increased compared with the cisplatin group $(\mathrm{P}<0.05)$. In
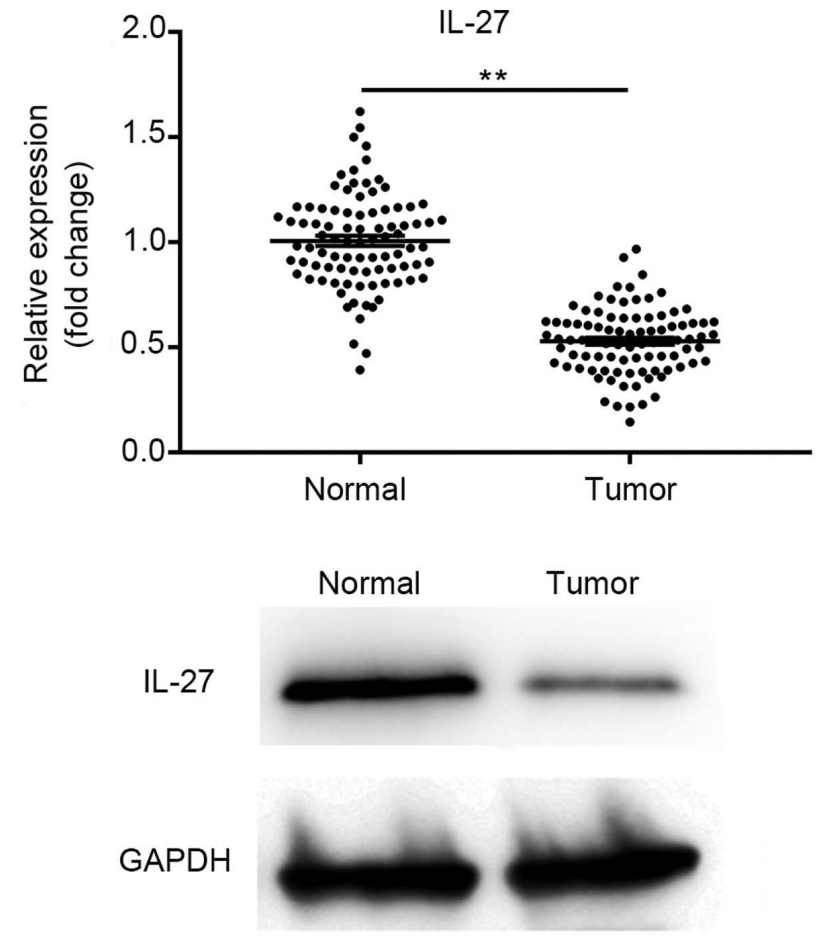

Figure 1. IL-27 is downregulated in lung cancer tissues. RT-qPCR and western blot analysis was performed to examine the expression of IL-27. Compared with the paracarcinoma tissues, the expression of IL-27 was significantly downregulated in cancer tissues. Data are presented as the mean \pm standard deviation. ${ }^{* *} \mathrm{P}<0.01$. IL-27, interleukin-27; RT-qPCR, reverse transcription-quantitative polymerase chain reaction.

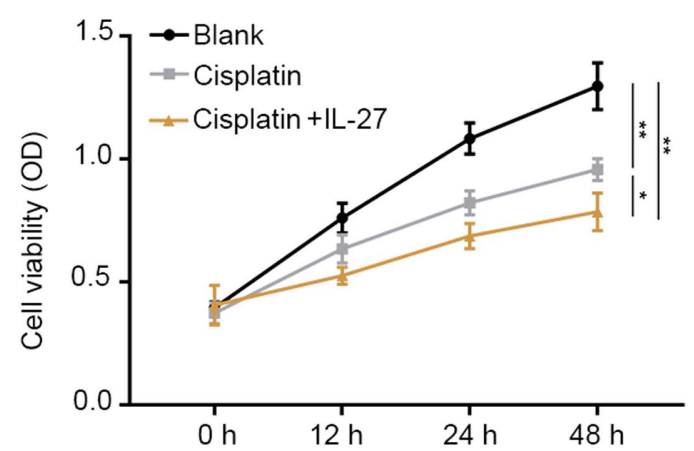

Figure 2. IL-27 inhibits the proliferation of A549 lung cancer cells. The proliferation rates of lung cancer cells were significantly suppressed following treatment with cisplatin, and were significantly inhibited in the cisplatin + IL-27 group, when compared with that in the control group. Data are presented as the mean \pm standard deviation. ${ }^{*} \mathrm{P}<0.05,{ }^{* *} \mathrm{P}<0.01$. IL-27, interleukin-27; OD, optical density.

summary, these data suggest that IL-27 is capable of inhibiting the proliferation ability of A549 lung cancer cells, enhancing apoptosis and promoting sensitivity to cisplatin.

IL-27 regulated Akt, Bcl-2, Bax and caspase-3 expression in A549 lung cancer cells. The RT-qPCR and western blot analysis of Akt, Bcl-2, Bax and caspase-3 corroborated the apoptosis assay results. The results of the RT-qPCR assay demonstrated that the expression levels of pro-apoptotic genes, including Bax and caspase-3, were significantly upregulated in the cisplatin group compared with that in the control group, 

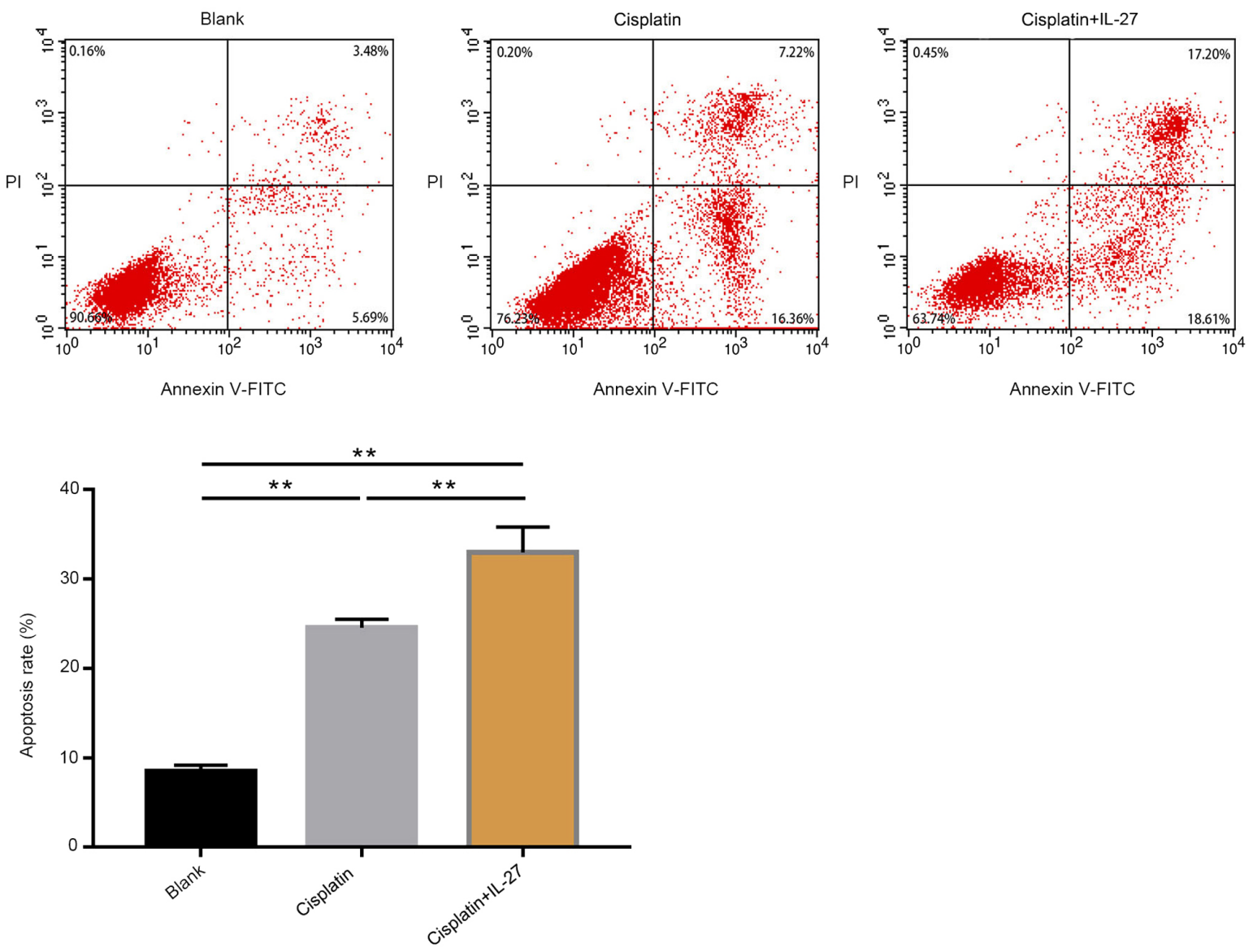

Figure 3. IL-27 promotes apoptosis in A549 lung cancer cells. Flow cytometry analysis was conducted to evaluate the rates of apoptosis in lung cancer cells, and apoptosis in cells treated with cisplatin + IL-27 was significantly increased. Data are presented as the mean \pm standard deviation. ${ }^{* *} \mathrm{P}<0.01$. IL-27, interleukin-27; PI, propidium iodide.

whereas the expression of the anti-apoptotic gene Bcl-2 was significantly downregulated in the cisplatin group compared with that in the control group (Fig. 4, $\mathrm{P}<0.01$ ). Furthermore, Bax and caspase- 3 expression levels in the cisplatin + IL-27 treatment group were significantly downregulated compared with that in the cisplatin alone group $(\mathrm{P}<0.01$; Fig. 4$)$, while the expression of Bcl-2 was significantly downregulated in the cisplatin + IL-27 treatment group compared with that in the cisplatin alone group. The results of the western blot analysis were consistent with those obtained by RT-qPCR (Fig. 5). The expression levels of Bax and caspase-3 in the cisplatin group were significantly increased, and the expression of Bcl-2 was significantly decreased when compared with the control $(\mathrm{P}<0.05)$; these effects were further enhanced in the cisplatin + IL-27 group. The relative expression levels of genes associated with apoptosis indicate that IL-27 can significantly increase the sensitivity of A549 lung cancer to cisplatin.

\section{Discussion}

Numerous studies have verified that IL-27 exhibits an antitumor function in various types of human cancer. It has previously been reported that IL-27 directly inhibits cell proliferation and angiogenesis in prostate cancer (27). Furthermore, transfection of human pancreatic carcinoma cells with IL-27 has previously been reported to inhibit proliferation, induce cell cycle arrest and promote apoptosis (28). Increasing the expression levels of IL-27, combined with treatment with rapamycin and cisplatin, has been demonstrated to inhibit the proliferation and metastasis of endometrial cancer (29). The findings of the present study suggest that IL-27 is downregulated in lung cancer tissues in comparison with that in normal tissues, and verified that IL-27 is an anti-oncogene, which is consistent with the findings of the aforementioned previous studies.

The potential mechanisms by which IL-27 promotes cisplatin chemosensitivity in lung cancer cells were investigated. The present study demonstrated that IL-27 induced chemosensitivity in human lung cancer cells by inhibiting proliferation and invasion, and promoting apoptosis. Cell viability was significantly inhibited in the cisplatin group, and these effects were even greater in the cisplatin + IL-27 group, concordant with the apoptosis assay results.

Subsequently, the underlying mechanisms by which IL-27 enhances lung cancer cell sensitivity to cisplatin were investigated. A previous study demonstrated that IL-27 could inhibit the proliferation of various cancer cells by suppressing the Akt signaling pathway (30). In a previous study, IL-27 and sorafenib each suppressed bladder cancer cell proliferation, migration and invasion, and increased apoptosis through the AKT/mTOR/mitogen-activated protein kinase pathway (31). It is hypothesized that IL-27 may strengthen the sensitivity 

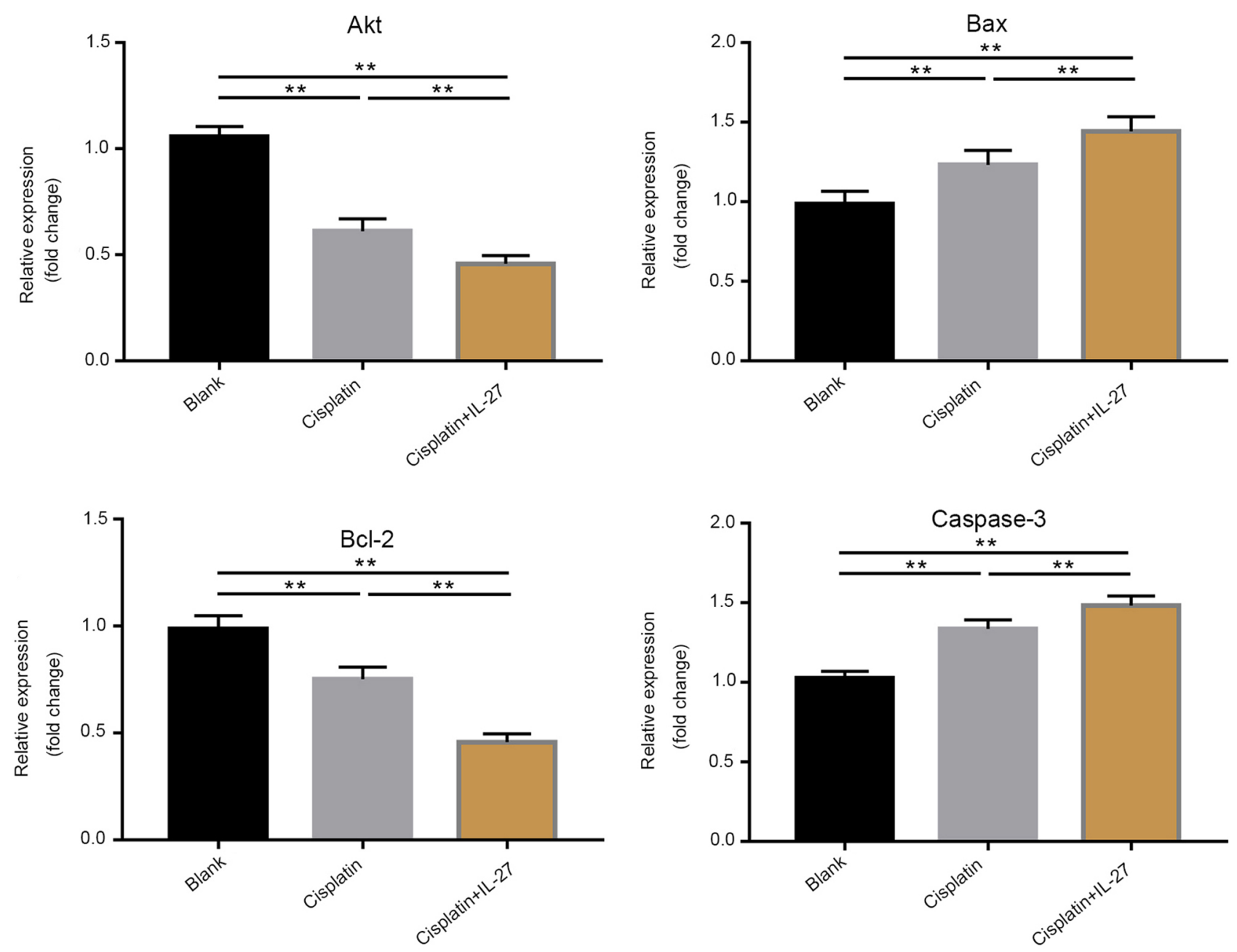

Figure 4. Cisplatin + IL-27 is more potent compared with cisplatin alone in regulating the mRNA level of Akt, Bcl-2/Bax, Caspase-3. Compared with control group, the mRNA levels of Akt and Bcl-2 in the cisplatin group were significantly increased; the mRNA levels were further increased in the cisplatin + IL-27 group. Data are presented as the mean \pm standard deviation. ${ }^{* *} \mathrm{P}<0.01$. IL-27, interleukin 27.

A

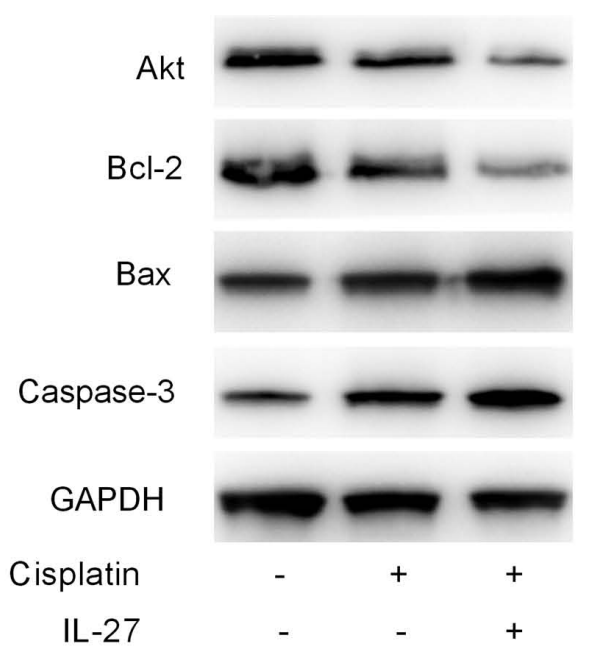

B

Control

Cisplatin+pcDNA3.1

Cisplatin+pcDNA3.1- IL-27

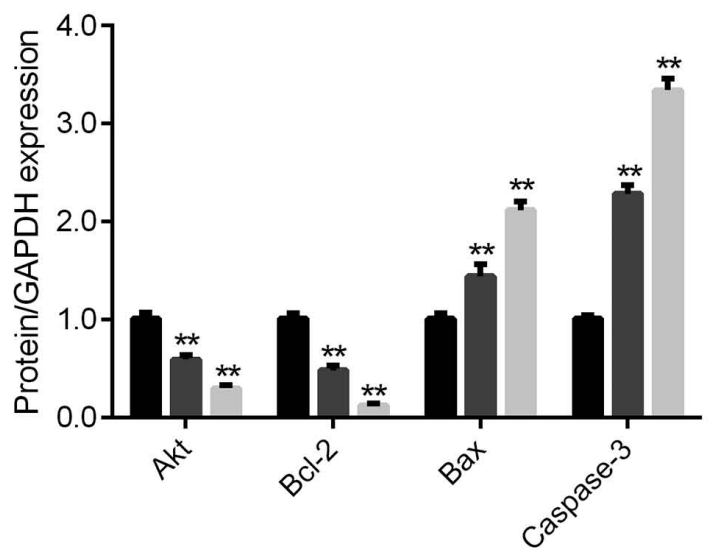

Figure 5. Protein expression in the Akt signaling pathway. (A) Treatment with cisplatin significantly increased the expression of Bax and Caspase-3, and decreased the expression of Bcl-2 and Akt compared with the control group. In addition, expression in the cisplatin + IL-27 group exhibited an increased effect. (B) Quantification of (A).** $\mathrm{P}<0.01$ vs. control. IL-27, interleukin-27. 
of lung cancer cells to drugs by inhibiting the Akt pathway. The present study revealed that treating lung cancer cells with cisplatin + IL-27 significantly decreased expression levels of the anti-apoptotic factors Akt and Bcl-2, and augmented expression of the apoptotic factors Bax and caspase-3. This was consistent with our hypothesis and the results obtained in previous studies $(31,32)$.

To the best of our knowledge, the present study is the first to investigate the mechanisms of IL-27 in enhancing the chemosensitivity of lung cancer cells to cisplatin. However, the present study was limited by a small patient cohort and, at present, lacks an efficient system to record patient outcomes.

In conclusion, the current data suggest that IL-27 may be a potential target for antitumor therapy. IL-27 can enhance the sensitivity of A549 cells to chemotherapeutic drugs by inhibiting the Akt pathway. These findings provide evidence that supports IL-27 as a potential biomarker and treatment strategy for patients with lung cancer, and lays a foundation for the application of IL-27 in a clinical setting.

\section{Acknowledgements}

Not applicable.

\section{Funding}

No funding was received.

\section{Availability of data and materials}

The datasets used and/or analyzed during the present study are available from the corresponding author on reasonable request.

\section{Authors' contributions}

BJ drafted the manuscript and cooperated with WS and PL to collect the data, and with YW and YL to analyze and interpret the data. CB was involved in the concept and design of the study.

\section{Ethics approval and consent to participate}

The present study was approved by the Ethics Committee of Suizhou Central Hospital (Suizhou, China) and all patients provided written informed consent prior to surgery.

\section{Patient consent for publication}

Not applicable.

\section{Competing interests}

The authors declare that they have no competing interests.

\section{References}

1. Gu Y, Liu S, Zhang X, Chen G, Liang H, Yu M, Liao Z, Zhou Y, Zhang CY, Wang T, et al: Oncogenic miR-19a and miR-19b co-regulate tumor suppressor MTUS1 to promote cell proliferation and migration in lung cancer. Protein Cell 8: 455-466, 2017.
2. Deng L, Tang Y, Lin J, Lu XJ, Xue JX, Wang LS, Zhou L, Zou Y, Ying BW, Li GD and Lu Y: Detection of epidermal growth factor receptor gene mutation in non-small cell lung cancer by allele-specific oligonucleotide-PCR and bi-loop probe specific primer quantitative PCR. Zhonghua Bing Li Xue Za Zhi 41: 20-22, 2012 (In Chinese).

3. Lo Russo G, Proto C and Garassino MC: Afatinib in the treatment of squamous non-small cell lung cancer: A new frontier or an old mistake? Transl Lung Cancer Res 5: 110-114, 2016.

4. Kazandjian D, Suzman DL, Blumenthal G, Mushti S, He K, Libeg M, Keegan P and Pazdur R: FDA approval summary: Nivolumab for the treatment of metastatic non-small cell lung cancer with progression on or after platinum-based chemotherapy. Oncologist 21: 634-642, 2016.

5. Antonia S, Goldberg SB, Balmanoukian A, Chaft JE, Sanborn RE, Gupta A, Narwal R, Steele K, Gu Y, Karakunnel JJ and Rizvi NA: Safety and antitumour activity of durvalumab plus tremelimumab in non-small cell lung cancer: A multicentre, phase 1b study. Lancet Oncol 17: 299-308, 2016.

6. Zhou YY, Hu ZG, Zeng FJ and Han J: Clinical profile of cyclooxygenase-2 inhibitors in treating non-small cell lung cancer: A meta-analysis of nine randomized clinical trials. PLoS One 11: e015193, 2016.

7. Fenchel K, Sellmann L and Dempke WC: Overall survival in non-small cell lung cancer-what is clinically meaningful? Transl Lung Cancer Res 5: 115-119, 2016.

8. Wang W, Zhang L, Wang Y, Ding Y, Chen T, Wang Y, Wang H, Li Y, Duan K, Chen S, et al: Involvement of miR-451 in resistance to paclitaxel by regulating YWHAZ in breast cancer. Cell Death Dis 8: e3071, 2017.

9. Wu D, Lu P, Mi X and Miao J: Downregulation of mir-503 contributes to the development of drug resistance in ovarian cancer by targeting pi3k p85. Arch Gynecol Obstet 297: 699-707, 2018.

10. Siddik ZH: Cisplatin: Mode of cytotoxic action and molecular basis of resistance. Oncogene 22: 7265-7279, 2003.

11. Dasari S and Tchounwou PB: Cisplatin in cancer therapy: Molecular mechanisms of action. Eur J Pharmacol 740: 364-378, 2014.

12. He L, Luo L, Zhu H, Yang H, Zhang Y, Wu H, Sun H, Jiang F, Kathera CS, Liu L, et al: FEN1 promotes tumor progression and confers cisplatin resistance in non-small-cell lung cancer. Mol Oncol 11: 640-654, 2017.

13. Zhang PF, Sheng LL, Wang G, Tian M, Zhu LY, Zhang R, Zhang $\mathrm{J}$ and Zhu JS: miR-363 promotes proliferation and chemo-resistance of human gastric cancer via targeting of FBW7 ubiquitin ligase expression. Oncotarget 7: 35284-35292, 2016

14. Krevvata M, Shan X, Zhou C, Dos Santos C, Habineza Ndikuyeze G, Secreto A, Glover J, Trotman W, Brake-Silla G, Nunez-Cruz S, et al: Cytokines increase engraftment of human acute myeloid leukemia cells in immunocompromised mice but not engraftment of human myelodysplastic syndrome cells. Haematologica 103: 959-971, 2018.

15. Nasiri M, Karimi MH, Azarpira N and Saadat I: Gene expression profile of toll-like receptor/adaptor/interferon regulatory factor/cytokine axis during liver regeneration after partial ischemia-reperfusion injury. Exp Clin Transplant, 2018 (Epub ahead of prin).

16. Jiang YX, Yang SW, Li PA, Luo X, Li ZY, Hao YX and Yu PW: The promotion of the transformation of quiescent gastric cancer stem cells by IL-17 and the underlying mechanisms. Oncogene 36: 1256-1264, 2016.

17. Mantovani A, Barajon I and Garlanda C: IL-1 and IL-1 regulatory pathways in cancer progression and therapy. Immunol Rev 281: 57-61, 2018.

18. Anuradha R, Munisankar S, Bhootra Y, Dolla C, Kumaran P, Nutman TB and Babu S: Modulation of CD4+ and CD8+ T Cell Function and Cytokine Responses in Strongyloides stercoralis Infection by Interleukin-27 (IL-27) and IL-37. Infect Immun 85: pii: e00500-17, 2017.

19. Xu L, Zhu LL, Ye LL, Meng LJ, Liu WQ and Wang J: Percentages of peripheral blood gammadelta t cells and regulatory t cells and expression of associated cytokines in infants with human cytomegalovirus infection. Zhongguo Dang Dai Er Ke Za Zhi 20: 204-208, 2018 (In Chinese).

20. Wu X, Tao P, Zhou Q, Li J, Yu Z, Wang X, Li J, Li C, Yan M, Zhu Z, et al: IL-6 secreted by cancer-associated fibroblasts promotes epithelial-mesenchymal transition and metastasis of gastric cancer via JAK2/STAT3 signaling pathway. Oncotarget 8: 20741-20750, 2017

21. Yu XX, Hu Z, Shen X, Dong LY, Zhou WZ and Hu WH: IL-33 promotes gastric cancer cell invasion and migration via ST2-ERK1/2 pathway. Dig Dis Sci 60: 1265-1272, 2015. 
22. KopinskiP,WandtkeT,WedrowskaEandChorostowska-WynimkoJ Interleukin 27 in bronchoalveolar lavage fluid in patients with nonsmall cell lung cancer. Authors' reply. Pol Arch Intern Med 128 266-268, 2018.

23. Liu Q, Yu YX, Wang XJ, Wang Z and Wang Z: Diagnostic accuracy of interleukin-27 between tuberculous pleural effusion and malignant pleural effusion: A meta-analysis. Respiration 95: 469-477, 2018.

24. Patel MV, Shen Z, Rossoll RM and Wira CR: IL-27 expression and responsiveness in human uterine epithelial cells and fibroblasts in vitro and the role of estradiol. J Interferon Cytokine Res 38: 101-110, 2018.

25. Zhu J, Liu JQ, Shi M, Cheng X, Ding M, Zhang JC, Davis JP, Varikuti S, Satoskar AR, Lu L, et al: IL-27 gene therapy induces depletion of tregs and enhances the efficacy of cancer immunotherapy. JCI Insight 3: pii: 98745, 2018.

26. Livak KJ and Schmittgen TD: Analysis of relative gene expression data using real-time quantitative PCR and the 2(-Delta Delta C(T)) method. Methods 25: 402-408, 2001.

27. Di Carlo E, Sorrentino C, Zorzoli A, Di Meo S, Tupone MG Ognio E, Mincione $\mathrm{G}$ and Airoldi I: The antitumor potential of Interleukin-27 in prostate cancer. Oncotarget 5: 10332-10341, 2014

28. Liu L, Meng J, Zhang C, Duan Y, Zhao L, Wang S and Shan B: Effects on apoptosis and cell cycle arrest contribute to the antitumor responses of interleukin-27 mediated by retrovirus in human pancreatic carcinoma cells. Oncol Rep 27: 1497-1503, 2012 .
29. Zhou WJ, Chang KK, Wu K, Yang HL, Mei J, Xie F, Li DJ and Li MQ: Rapamycin synergizes with cisplatin in antiendometrial cancer activation by improving IL-27-stimulated cytotoxicity of NK cells. Neoplasia 20: 69-79, 2018

30. Zhang Z, Zhou B, Zhang K, Song Y, Zhang L and Xi M: IL-27 suppresses SKOV3 cells proliferation by enhancing STAT3 and inhibiting the Akt signal pathway. Mol Immunol 78: 155-163, 2016.

31. Cao JY, Yin HS, Li HS, Yu XQ and Han X: Interleukin-27 augments the inhibitory effects of sorafenib on bladder cancer cells. Braz J Med Biol Res 50: e6207, 2017.

32. Liu Z, Liu JQ, Talebian F, Wu LC, Li S and Bai XF: IL-27 enhances the survival of tumor antigen-specific CD8+ T cells and programs them into IL-10-producing, memory precursor-like effector cells. Eur J Immunol 43: 468-479, 2013.

(i) (9) This work is licensed under a Creative Commons Attribution-NonCommercial-NoDerivatives 4.0 International (CC BY-NC-ND 4.0) License. 